\title{
Characterization of Fasciola gigantica isolates from cattle from South-western Zimbabwe using RAPD-PCR
}

\author{
${ }^{1}$ E. Chauke, ${ }^{1}$ Z. Dhlamini, ${ }^{1}$ J. Mbanga, ${ }^{1 *}$ S. Dube \\ ${ }^{I}$ Department of Applied Biology and Biochemistry, National University of Science and Technology, Zimbabwe
}

\begin{abstract}
The study sought to characterize Fasciola gigantica isolates from cattle in different localities using RAPD-PCR. Adult flukes morphologically identified as F. gigantica were collected from slaughtered infected animals during meat hygiene inspections. DNA was extracted from single flukes and subjected to RAPD-PCR analysis. In the RAPD-PCR analysis, genomic DNA isolated from the conical anterior end of the worms was amplified by the polymerase chain reaction using 10 random oligonucleotide primers. Depending upon the Fasciola gigantica isolate-primer combination, 1-13 DNA fragments in the range of 75-2000bp were amplified. It was observed that all the 10 primers directing amplification of DNA were of potential interest in the generation of polymorphic DNA. The percentage polymorphic loci ranged from 33.33-100\%. Polymorphic bands were scored and used to calculate Nei's 1978 genetic distance. The genetic distance values ranged between 0.0690 (isolate 5 and 6 from Gwanda and 0.6109 (isolate 6 from Gwanda and isolate 14 from Matopo). The mean Nei's gene diversity was 0.2839. The study showed the variability of Fasciola gigantica isolates from the same host, using RAPD markers could be applied as a low cost way of identification.
\end{abstract}

Keywords; Cattle, Fasciola, morphology, RAPD-PCR, Zimbabwe.

\section{INTRODUCTION}

Fasciola is a genus of trematodes that comprises species of economic importance. Besides causing liver condemnations, high mortality rate, reduced production of meat and milk in the cattle industry. Fasciola spp. are responsible for infecting millions of people worldwide [1, 2, 3]. Fasciola gigantica and Fasciola hepatica cause fasciolosis an important food-and-water borne parasitic zoonosis [1, 4].

Fasciolosis, caused by Fasciola, is one of the most important helminth infections of human and livestock in many parts of the world. In humans fasciolosis is focal in distribution and sporadic while in ruminants the infection is principally endemic and of greatest economic importance [5]. Annual economic losses caused by the disease in the Agriculture sector are estimated to be US $\$ 2$ billion worldwide mainly due to condemned livers, reduced milk yield, fertility disorders and reduced meat production $[1,6]$. A wide variety of wild animals including deer, rabbit and hare, may get infected with Fasciola spp. and these become major reservoir host populations that contribute significantly to the worldwide dissemination of the parasite [7]. Human Fasciolosis has been reported in many countries worldwide. It is estimated that $2.4-17$ million people are infected with one or both species of the liver fluke, namely Fasciola hepatica and Fasciola gigantica, often causing serious acute and chronic morbidity [8]. Serious under reporting of this zoonotic disease is suspected, caused by limitations of accurate diagnosis, and because human fasciolosis is not a notifiable disease [1].

Fasciola gigantica; is most prevalent in the tropics, such as parts of Africa, the Indian subcontinent, and certain Islands in the Pacific [9]. Fasciola hepatica has a widespread distribution and is found in Europe, Africa, Asia, Australia, and North and South America. In some parts of the world the two parasites co-exist but it is not certain to what extent competition between them occurs. The prevalence rates for fasciolosis can be as high as 30\% to $90 \%$ and it is often considered to be the most important cattle helminth infection [9].

Molecular makers are a useful tool for genetic characterization and studies of genetic variability among parasite populations $[10,11]$. The random amplified polymorphic DNA (RAPD) technique is a PCR-based method that uses a short primer, which is usually 10 bases to amplify anonymous stretches of DNA. This method has proved to be a powerful and rapid method for detecting polymorphic genetic variation. With this technique, there is no specific target DNA, so each particular primer will adhere to the template DNA randomly and prior sequence information is not required, which makes it a convenient alternative to other molecular methods that have been used [12, 13]. Polymorphic genetic variation can be used in population and phylogenetic studies in identification of parasite strains and species and in comparison of field isolates. The RAPD (random-amplification-of-polymorphic-DNA) method has been used successfully in the study of interand intraspecific variation of Fasciola spp. [6, 14, 15, 16].

In Zimbabwe no study on molecular characteristics of Fasciola gigantica has been done. The most often used methods for taxonomical and population studies have been morphological but recently molecular and genetic techniques have been utilized, in addition to the classical methods. The aim of this study was to 
characterize Fasciola gigantica isolates using morphological features and to detect polymorphic genetic variation between the isolates of Fasciola gigantica isolated from cattle in different geographical locations using RAPD-PCR.

\section{Materials And Methods}

Sample collection and Morphological identification: Adult trematodes were collected at necropsy during slaughter inspection from bile ducts of livers of cattle brought to abattoirs in Bulawayo, Zimbabwe, between February and April 2013 (Table 1). Flukes were extensively washed with distilled water and identified morphologically as Fasciola gigantica according to existing keys (body length (BL), body width (BW), body length to width ration (BL/BW); Cone Length (CL); appearance of body sides and shoulder characteristics) as described by other authors $[17,18]$ and stored at $-70^{\circ} \mathrm{C}$ until extraction of genomic DNA.

Table 1: Liver Fluke isolates collected from abattoir and their districts of origin

\begin{tabular}{lccc}
\hline District of origin & Coordinates & Number of cattle & Sample number \\
\hline Gwanda & $-20.93611,29.015579$ & 4 & $1-6$ \\
Plumtree & $-20.491346,27.81189$ & 5 & $7-11$ \\
Matopo & $-20.505978,28.435214$ & 3 & $12-14$ \\
Bulawayo & $-20.141049,28.578186$ & 2 & 15 and 16 \\
Mangwe & $-20.635355,28.061829$ & 1 & 17 \\
\hline
\end{tabular}

Total genomic DNA extraction: Body portions (the conical anterior end) from individual trematodes were each placed in $200 \mu \mathrm{l}$ of sterile lysis buffer, containing $0.4 \mathrm{M} \mathrm{NaCl}, 10 \mathrm{mM}$ Tris-HCl (pH 8$)$ and $2 \mathrm{mM}$ EDTA ( $\mathrm{pH} \mathrm{8)}$ ) and crushed using a sterile pestle and mortar. After homogenisation the mixture was pipetted into $1.5 \mathrm{ml}$ eppendorf tubes and $40 \mu \mathrm{l}$ of $20 \% \mathrm{SDS}$ added. An aliquot of $3 \mu \mathrm{l}$ of proteinase $\mathrm{K}\left(20 \mathrm{mgml}^{-1}\right)$ was added to each tube, which was incubated at $55^{\circ} \mathrm{C}$ for 1 hour. An aliquot of $3 \mu \mathrm{l}$ of RNAse solution $\left(4 \mathrm{mgml}^{-1}\right) \mathrm{was}^{\circ}$ added and the tubes incubated at $37^{\circ} \mathrm{C}$ for $30 \mathrm{~min}$. Subsequently $1 / 10$ the sample volume of $5 \mathrm{M} \mathrm{NaCl}$ was added to the tubes and placed on ice for 1 hour and then centrifuged at 7000RPM for 10 min. The supernatant was transferred to a clean tube. DNA was precipitated with ethanol. The precipitated DNA was pelleted by centrifugation at 12000RPM for $5 \mathrm{~min}$ at room temperature, and then the pellet was washed with $70 \%$ ethanol twice. Each DNA pellet was air-dried for $20 \mathrm{~min}$ and dissolved in $100 \mu \mathrm{l}$ of nuclease free water. The samples were kept at $-20^{\circ} \mathrm{C}$ until use. The purity and the concentration of the isolated DNA was determined by ethidium bromide stained agarose gel $(0.8 \% \mathrm{w} / \mathrm{v})$ electrophoresis.

Random amplification of polymorphic DNA (RAPD): Twenty-four primers were screened of which 10 (OPAB-08, OPAE-14; OPAH-18; OPAQ-16; OPAR-17; OPAU-19; OPG-06; OPM-17; OPN-13; from eurofins and OPG-08 from Inqaba Biotec) were chosen for use as arbitrary primers (APs) in RAPD assays to discern the variability, between the Fasciola gigantica isolates, based on the quality of amplification and polymorphism they produced (Table 2). Initial experiments to optimize RAPD reaction conditions for Fasciola gigantica DNA templates involved the empirical variation of annealing temperature, DNA concentration, primer concentration, $\mathrm{MgCl}_{2}$, and Dream Taq DNA polymerase concentration. A negative control (containing all the reaction components except the DNA template) was run for every RAPD analysis done. Amplification reactions were carried out in a $20 \mu \mathrm{l}$ reaction, which contained template DNA (50 ng), $2 \mu \mathrm{l}$ of 10X Dream Taq DNA polymerase buffer (Thermo Scientific, USA), $2 \mu \mathrm{l}$ of dNTP mix $(10 \mathrm{mM}), 2 \mu \mathrm{l}$ of Q-solution (PCR enhancer, Qiagen), $2 \mu \mathrm{l}$ of primer $(100 \mu \mathrm{M}), 2 \mu \mathrm{MgCl}_{2}(25 \mathrm{mM})$ and $1.25 \mathrm{U}$ of Dream Taq DNA polymerase (Thermo Scientific, USA). Amplification was performed in a DNA thermal cycler (Gene Amp* PCR system-9700, Applied Biosystems, Singapore) with a preheated lid programmed with initial denaturation temperature at $95^{\circ} \mathrm{C}$ for $2 \mathrm{~min}$, followed by 40 cycles each of denaturation at $95^{\circ} \mathrm{C}$ for $30 \mathrm{~s}$, annealing at $40^{\circ} \mathrm{C}$ for $45 \mathrm{~s}$, and extension at $72^{\circ} \mathrm{C}$ for $1 \mathrm{~min} 30 \mathrm{~s}$, followed by a final extension cycle at $72^{\circ} \mathrm{C}$ for $15 \mathrm{~min}$. Amplification products were separated by gel electrophoresis in a $1.5 \% \mathrm{w} / \mathrm{v}$ ethidium bromide stained agarose gel. The gels were then photographed under UV light using a Gel Documentation system (Uvitec, Cambridge, UK). DNA fragments were scored from photographs of the gels.

Gene diversity and phylogenetic analysis of the RAPD profile: Genetic variation was estimated using the PopGen32 software package (version 1.32, University of Alberta, California) and the following indices were calculated: percentage of polymorphic loci $\left(\mathrm{P}=\mathrm{n}_{\mathrm{pj}} / \mathrm{n}_{\mathrm{total}}\right)$, where $\mathrm{n}_{\mathrm{pj}}=$ number of polymorphic loci and $n_{\text {total }}=$ total number of loci; Nei's, 1978 genetic distance, and Nei's (1973) gene diversity. The latter was adopted assuming the populations to be in Hardy-Weinberg equilibrium, although we were not able to investigate this since dominant markers were used. Unweighted Pair Group Method with Arithmetic mean (UPGMA) of the RAPD profile was carried out to analyze the phylogenetic relationships between the worms. This analysis was done after plotting Nei's unbiased genetic distance matrix, using PopGene32 software. 


\section{RESULTS}

Morphological Characterization: All the seventeen flukes used in this study were identified morphologically as $F$. gigantica according to existing keys and descriptions (Table 2). In the present study four useful morphometrical parameters (BL, BW, BL/BW, and $\mathrm{CL}$ ) used for species differentiation, were considered for phenotypic characterization of fasciolids. The samples could not be differentiated by locality in terms of morphological characteristics. The body length (BL) of the worms used in the present study ranged from $34-40$ $\mathrm{mm}$, the body width (BW) range from $7-11 \mathrm{~mm}$, the body length to width ratio (BL/BW) ranged from $3.5-$ 4.9 and the cone length (CL) ranged from $3-4 \mathrm{~mm}$. All the flukes used in the present study had parallel body sides and a barely perceptible shoulder characteristic.

Table 2: Morphological characterization of Fasciola Samples collected from cattle from Abattoirs in Bulawayo,

\begin{tabular}{|c|c|c|c|c|c|}
\hline District of Origin & Sample number & BL (mm) & BW (mm) & BL/BW & CL (mm) \\
\hline \multirow{6}{*}{ Gwanda } & 1 & 35 & 10 & 3.5 & 3.0 \\
\hline & 2 & 34 & 7 & 4.9 & 3.0 \\
\hline & 3 & 34 & 9 & 3.8 & 3.0 \\
\hline & 4 & 36 & 9 & 4.0 & 4.0 \\
\hline & 5 & 36 & 10 & 3.6 & 4.0 \\
\hline & 6 & 35 & 10 & 3.5 & 3.0 \\
\hline \multirow[t]{5}{*}{ Plumtree } & 7 & 35 & 8 & 4.4 & 4.0 \\
\hline & 8 & 34 & 9 & 3.8 & 4.0 \\
\hline & 9 & 45 & 11 & 4.1 & 4.0 \\
\hline & 10 & 38 & 10 & 3.8 & 3.8 \\
\hline & 11 & 35 & 10 & 3.5 & 3.0 \\
\hline \multirow[t]{3}{*}{ Matopo } & 12 & 36 & 9 & 4.0 & 4.0 \\
\hline & 13 & 37 & 10 & 3.7 & 3.8 \\
\hline & 14 & 40 & 10 & 4.0 & 4.0 \\
\hline \multirow[t]{2}{*}{ Bulawayo } & 15 & 35 & 9 & 3.9 & 4.0 \\
\hline & 16 & 38 & 10 & 3.8 & 4.0 \\
\hline Mangwe & 17 & 39 & 11 & 3.5 & 4.0 \\
\hline
\end{tabular}

BL: Body Length; BW: Body Width; BL/BW: Body length to width ratio

Degree of polymorphism in Fasciola gigantica as revealed by RAPDs: All ten primers used in this study produced amplifications and they were all multiple band profiles. The RAPD amplification yielded between 1(primer OPM-17 and isolate 3, OPN-13 and isolate 14 and OPAU-19 and isolate 17) and 13 (primer OPAR-17 and isolate 5) DNA fragments in the size range of 75 to 2000bp. The characteristics of fragments generated by the 10 primers selected for the genetic analysis are shown in Table 3 . The ten primers produced 105 loci of which 90 were polymorphic and the percentage of polymorphic loci was: 85.71. Fig 1 shows the RAPD banding pattern obtained with primer OPG-08 (TCACGTCCAC). The mean Nei's (1973) gene diversity was found to be 0.2839 . The matrix shown in Table 4 was obtained by using Nei's genetic distance coefficient in PopGen32 software for determining the genetic distances between Fasciola gigantica samples. The matrix (Table 4) shows genetic distance as derived from primers OPAB-08, OPAE-14; OPAH-18; OPAQ-16; OPAR-17; OPAU-19; OPG-06; OPM-17; OPN-13; from eurofins and OPG-08 from Inqaba Biotec for the 17 Fasciola gigantica isolates. Genetic distance values ranged between 0.0690 (isolate 5 and 6 from Gwanda) and 0.6109 (isolate 6 from Gwanda and isolate 14 from Matopo). As a result of cluster analysis conducted using UPGMA method, a dendrogram of the 17 Fasciola gigantica isolates was developed (Fig 2). The dendrogram of genetic distances constructed using the UPGMA algorithm produced 2 clusters, 1 small cluster with isolate 5 and 6, from Gwanda, and the major cluster with all the other Fasciola isolates (Fig 2). The dendrogram was divided into five groups, groups A-E. In group A, sample number 1, 2 and 3 from Gwanda were clustered, in group B, sample number 10 from Plumtree and sample number 13 from Matopo were clustered, in group C, sample number 7 and 11 from Plumtree and samples 14 and 17 from Matopo and Mangwe respectively were clustered, in group D, sample number 12 from Matopo and sample number 16 from Bulawayo were not clustered, in group E, sample 5 and 6 from Gwanda were the most similar samples in the study. 


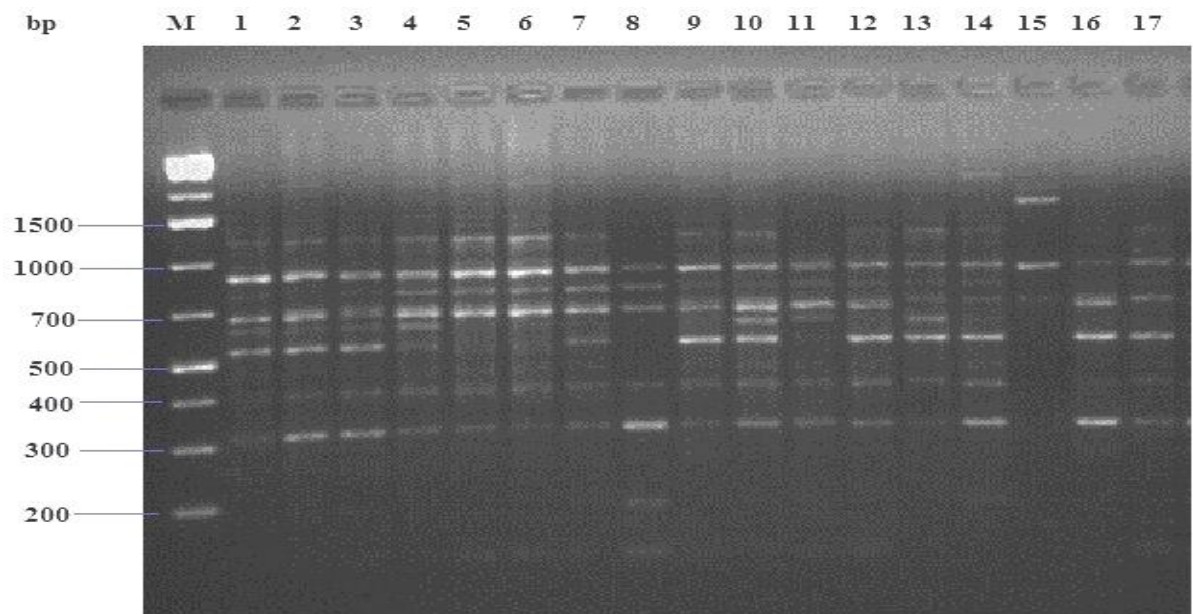

Figure 2: Gel image of RAPD fingerprint analysis of template DNA from Fasciola gigantica and 10-baseprimer OPG-08 (Inqaba Biotec). Lane M 1kb DNA ladder. Lane 1-17 Fasciola gigantica isolates.

Table 3: Characteristics of fragments generated by the 10 primers selected for the genetic analysis. Percentage Polymorphic loci $=($ Number of polymorphic fragments $\div$ Total number of loci) $\mathrm{X} 100$

\begin{tabular}{|c|c|c|c|c|c|c|}
\hline Primer code & Sequence 5'-3' & GC (\%) & $\begin{array}{c}\text { Total number } \\
\text { of loci }\end{array}$ & $\begin{array}{c}\text { Number of } \\
\text { polymorphic } \\
\text { fragments }\end{array}$ & $\begin{array}{c}\text { Percentage } \\
\text { Polymorphic } \\
\text { loci } \\
\end{array}$ & $\begin{array}{l}\text { Molecular weight } \\
\text { range in bp }\end{array}$ \\
\hline OPAB-08 & GTTACGGACC & 60 & 11 & 9 & 81.8 & $200-1000$ \\
\hline OPAE-14 & GAGAGGCTCC & 70 & 8 & 6 & 75 & $75-1500$ \\
\hline OPAH-18 & GGGCTAGTCA & 70 & 8 & 7 & 87.5 & $200-1500$ \\
\hline OPAQ-16 & CCCGGAAGAG & 70 & 3 & 1 & 33.3 & $700-2000$ \\
\hline OPAR-17 & CCACCACGAC & 70 & 16 & 15 & 93.8 & $200-2000$ \\
\hline OPAU-19 & AGCCTGGGGA & 70 & 21 & 21 & 100 & $200-1500$ \\
\hline OPG-06 & GTGCCTAACC & 60 & 10 & 6 & 60 & $200-1500$ \\
\hline OPG-08 & TCACGTCCAC & 60 & 14 & 12 & 85.7 & $75-1500$ \\
\hline OPM-17 & TCAGTCACTC & 60 & 8 & 7 & 87.5 & $200-1500$ \\
\hline OPN-13 & AGCGTCACTC & 60 & 6 & 6 & 100 & $200-1500$ \\
\hline
\end{tabular}

Table 4: Nei's Unbiased Measures of Genetic distance obtained from the ten arbitrary primers used in this study for 17 Fasciola gigantica isolates.

\begin{tabular}{cccccccccccccccccc}
\hline $\begin{array}{c}\text { Fasciola } \\
\text { isolate }\end{array}$ & 1 & 2 & 3 & 4 & 5 & 6 & 7 & 8 & 9 & 10 & 11 & 12 & 13 & 14 & 15 & 16 & 17 \\
\hline 1 & $* * * *$ & & & & & & & & & & & & & & & \\
2 & 0.2472 & $* * * *$ & & & & & & & & & & & & & & \\
3 & 0.2595 & 0.2231 & $* * * *$ & & & & & & & & & & & & & \\
4 & 0.2973 & 0.2845 & 0.3232 & $* * * *$ & & & & & & & & & & & & \\
5 & 0.3232 & 0.2845 & 0.3232 & 0.3635 & $* * * *$ & & & & & & & & & & & \\
6 & 0.3365 & 0.3232 & 0.3913 & 0.4643 & 0.0690 & $* * * *$ & & & & & & & & & & \\
7 & 0.2973 & 0.3365 & 0.3232 & 0.3102 & 0.3635 & 0.4345 & $* * * *$ & & & & & & & & & \\
8 & 0.3635 & 0.4643 & 0.3913 & 0.4345 & 0.4345 & 0.4796 & 0.2973 & $* * * *$ & & & & & & & & & \\
9 & 0.3232 & 0.3635 & 0.3499 & 0.3635 & 0.3913 & 0.4345 & 0.2595 & 0.2472 & $* * * *$ & & & & & & & & \\
10 & 0.2719 & 0.3365 & 0.3232 & 0.3365 & 0.3365 & 0.3232 & 0.3365 & 0.4345 & 0.2845 & $* * * *$ & & & & & & & \\
11 & 0.3913 & 0.5268 & 0.4796 & 0.4643 & 0.5935 & 0.5764 & 0.2231 & 0.3102 & 0.3232 & 0.4345 & $* * * *$ & & & & & & \\
12 & 0.3635 & 0.4643 & 0.4796 & 0.4345 & 0.4951 & 0.5431 & 0.4643 & 0.4199 & 0.4643 & 0.3773 & 0.3102 & $* * * *$ & & & & & \\
13 & 0.2719 & 0.2845 & 0.3232 & 0.3365 & 0.3635 & 0.3499 & 0.2595 & 0.3232 & 0.2845 & 0.2595 & 0.2973 & 0.3499 & $* * * *$ & & & & \\
14 & 0.4199 & 0.4055 & 0.3913 & 0.4055 & 0.5596 & 0.6109 & 0.3499 & 0.4199 & 0.3499 & 0.4055 & 0.2595 & 0.3635 & 0.2973 & $* * * *$ & & & \\
15 & 0.2973 & 0.2845 & 0.3232 & 0.3635 & 0.4199 & 0.4345 & 0.2845 & 0.3499 & 0.2595 & 0.3102 & 0.3773 & 0.4951 & 0.2595 & 0.3232 & $* * * *$ & & \\
16 & 0.3232 & 0.2845 & 0.3773 & 0.3913 & 0.4493 & 0.4643 & 0.3913 & 0.3773 & 0.4493 & 0.4493 & 0.4345 & 0.4951 & 0.3102 & 0.4055 & 0.3913 & $* * * *$ & \\
17 & 0.3232 & 0.3102 & 0.3773 & 0.3635 & 0.4493 & 0.4643 & 0.2595 & 0.3773 & 0.3365 & 0.3365 & 0.2472 & 0.3232 & 0.3102 & 0.2231 & 0.2351 & 0.3635 & $* * * *$ \\
\hline
\end{tabular}




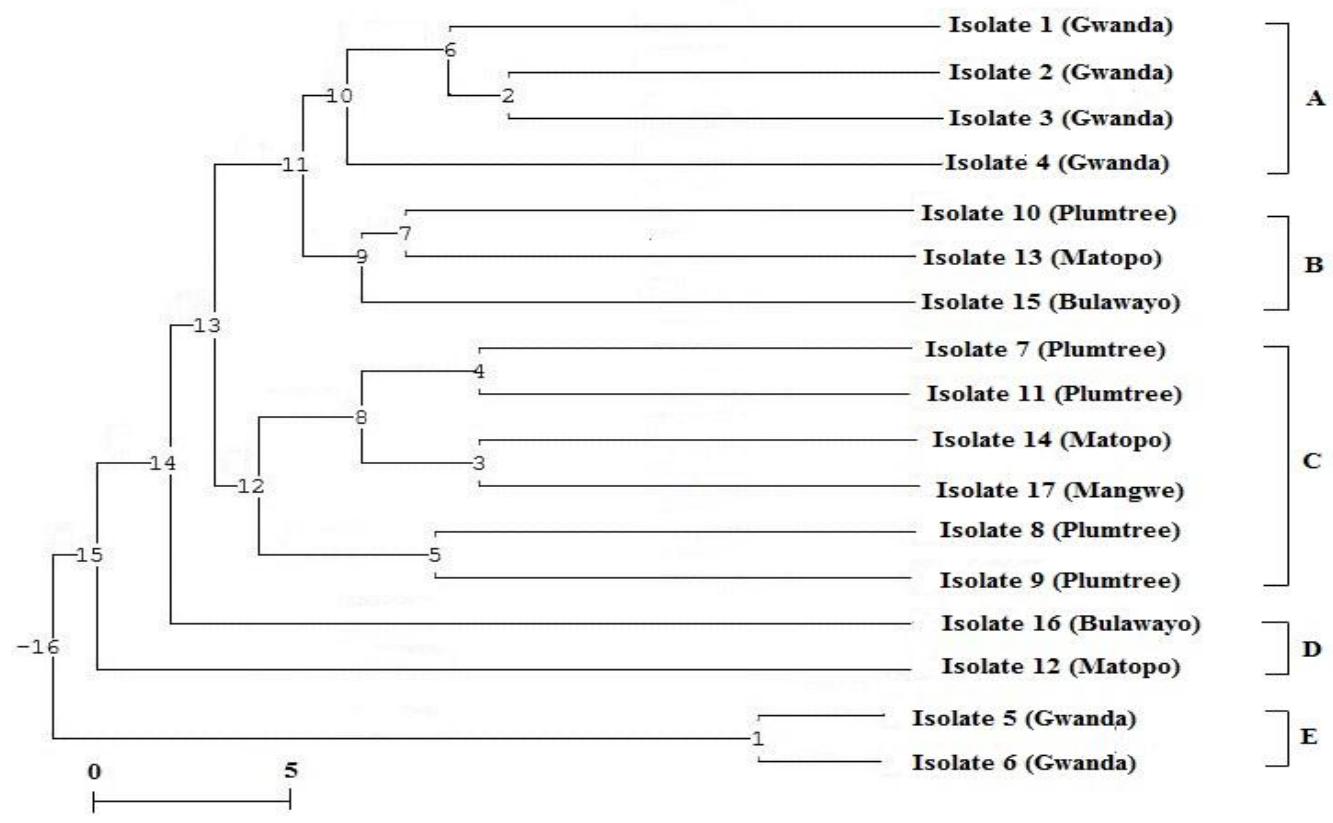

Figure 4: Dendrogram based on UPGMA of RAPD profiles, showing relationships among the 17 Fasciola gigantica isolates

\section{IV.}

\section{DISCUSSION}

Species identification in the present study was done by emphasizing BL, BW, CL indices and BL/BW ratios as suggested in previous studies [19, 20, 21]. Groups based on maximum and minimum values of the morphological measurements of Fasciola hepatica, Fasciola gigantica or Fasciola sp. (intermediate/hybrid forms) have been proposed for populations from Egypt and Iran [18], whereas, some authors have outlined some useful morphometric descriptions for the specific differentiation of the two species [21]. The basis of grouping was initially performed according to $\mathrm{BL} / \mathrm{BW}$, and, secondarily, according to Distance between ventral sucker and posterior end of the body (VS-P). The BL, BW, CL and BL/BW ratio of Fasciola isolates used in the present study resembled the Egyptian and Iranian F. gigantica [18].

In order to attain maximum precision in the morphological identification in this study, the liver flukes used were isolated from naturally infected cattle and were of the same size and maturity. In the present study, all the worms were similar to descriptions of Fasciola gigantica, especially in their length and shape as suggested by many authors, but some consider patterns of the reproductive organs and intestines as a differentiating factor also, but the natural branching shape of these structures makes this characteristic problematic [22]. The presence of intra-species morphometric differences and significant overlaps of these indices between the two species, means that morphometric measurements alone are insufficient for differential diagnosis of the fasciolid species. Therefore, in this study the $F$. gigantica was also genetically characterized using appropriate genetic markers.

There has been no data regarding genetic characterization of $F$. gigantica in Zimbabwe using defined DNA sequences. This study was carried out to characterize $F$. gigantica isolates from cattle from different geographical locations, using RAPD-PCR. RAPD polymorphism has been used for estimating genetic variability within and between parasite species and for evaluating genetic relationships between populations [6]. The use of a high annealing temperatures as in the case of the present study $\left(40{ }^{\circ} \mathrm{C}\right)$ increased the stringency of the PCR and ensured the reproducibility of RAPD results. To avoid getting spurious results the extent of genetic diversity in $F$. gigantica was investigated using 10 single arbitrary oligonucleotide primers. All 10 random primers used in the RAPD assays, had a GC content of between $60 \%$ and $70 \%$ and were able to direct amplification of the DNA fragments from the genome of Fasciola gigantica. A typical RAPD amplification yielded between 1(primer OPM-17 and isolate 3, OPN-13 and isolate 14 and OPAU-19 and isolate 17) and 13 (OPAR-17 and isolate 5) DNA fragments in the size range of 75 to $2000 \mathrm{bp}$ of which all were reproducible. All the primers used in this work were very informative with percentage polymorphic loci ranging from $33.33 \%$ - $100 \%$ for each primer (Table 3).

On the basis of genetic distance data (Table 4), liver flukes used in this study showed great variation with a range of 0.0690 - 0.6109 as compared to the findings by other authors in their study on the genetic variation of Fasciola hepatica isolates from sheep, cattle and buffalo, they found the interspecific genetic distance to range between 0.22 and 0.50 and intraspecific genetic distance ranged between 0 and 0.22 [23]. In a study on the Molecular differentiation of sheep and cattle isolates of Fasciola hepatica using RAPD-PCR the 
interspecific genetic distance had a range of 0.19-0.47 and intraspecific genetic distances had a range of 0-0.19 [24]. RAPD variability and genetic diversity for $F$. hepatica in particular have been examined in cattle populations of liver fluke from Ukraine and Armenia [25]. Studies [16, 24, 25] suggested multiple genetically different parasites but did not provide adequate information about genetic diversity, distribution and population structure of studied liver fluke isolates. Specific RAPD assays have been developed for differentiation of fasciolid species in UK, Peru, Ghana and Sudan [26]; and the technique enabled differentiation of $F$. hepatica and $F$. gigantica from cattle and sheep hosts from countries mentioned above. All liver flukes have been correctly identified to species level. Some investigations do not give detailed and complete information for genetic structure and diversity of liver fluke intrapopulations and do not established intra- and interpopulation relationships in different geographic regions [16, 24, 26].

This study demonstrates clearly that genetic heterogeneity exists within F. gigantica in Zimbabwe. There is evidence to infer the existence of some degree of genetic variation among $F$. gigantica isolates derived from cattle (the mean Nei's (1973) gene diversity was 0.2839). Similarly, other authors indicated to the high levels of genetic variability within $F$. hepatica from Spain using Allozyme markers (Nei's unbiased genetic diversity within populations ranged from 0.146 to 0.168 ) [27].

Cluster analysis of the RAPD profiles data (considering all polymorphic bands) showed a lack of separation in the dendrogram which reflects a weak genetic differentiation among the isolates. Previous studies $[28,29]$ focusing on geographic comparisons showed low divergence among isolates. Our cluster analysis did not show a relationship among $F$. gigantica isolates and their geographical location. Thus, the different samples of $F$. gigantica from different districts were intermingled in different parts of the UPGMA (Fig 2). However, it was possible to score relationships between some samples on the basis of their place of origin, in Group A and Group E we had isolates from Gwanda. The limited number of isolates in the present study and previous studies $[28,29]$ perhaps missed the intraspecies phylogenetic structure. In Group D we have isolate 15 from Bulawayo and isolate 11 from Matopo which are not clustered, these isolates are completely separate from all the other isolates in the major cluster and this implies that they are substantially genetically different from the other isolates. In any case, genetic differentiation between samples was independent of geographical distances. This may be due to animal movements which results in the co-migration of the parasites they carry.

\section{CONCLUSION}

In conclusion, the results of this study suggest the variability of Fasciola gigantica isolates in Zimbabwe, using RAPD markers. The findings of the present study on the variability of $F$. gigantica isolates from South Western Zimbabwe may have implications in the epidemiology and control programs of fasciolosis as a major helminth zoonosis of medical and veterinary importance.

\section{ACKNOWLEDGEMENTS}

This work was supported by funds provided by the Research Board, National University of Science and Technology, Bulawayo, Zimbabwe.

\section{REFERENCES}

[1] S. Mas-Coma, M. D. Bargues, and M. A. Valero, 2005, Fascioliasis and other plant-borne trematode zoonoses, Int J Parasitol, 35, $2005,1255-1278$.

[2] H. Le, N. V. De, T. Agatsuma, D. Blair, J. Vercruysse, P. Dorny, T. G. Nguyen, and D. P. McManus, Molecular confirmation that Fasciola gigantica can undertake aberrant migrations in human hosts, J Clin Microbiol, 145, 2007, 648 - 650.

[3] D. Liu, Human Parasitic Pathogens (Tylor and Francis Group LLC, USA, 2013) 87 - 120.

[4] P. Zhou, N. Chen, R. L. Zhang, R. Q. Lin, and X. Q. Zhu, Food-borne parasitic zoonoses in China: perspective for control, Trends Parasitol, 24, 2008,190-196.

[5] G. U. Schweizer, P. D. Braun, and P. R. Torgerson, Estimating the financial losses due to bovine fasciolosis in Switzerland. Vet Rec, 157, 2005, $188-193$.

[6] M. Rokni, H. Mirhendi, M. Behnia, M. Fasihi, and N. Jalalizand, Molecular Characterization of Fasciola hepatica Isolates by RAPD-PCR and Ribosomal ITS1 Sequencing, IRCMJ, 12, 2010, 27 - 32.

[7] WHO, Report of a WHO informal meeting on the use of Triclabendazole in Fascioliasis control, World Health Organization, Geneva Switzerland, 2007.

[8] X. Zhou, R. Bergquist, R. Olveda, and J. Utzinger, Advances in parasitology, volume 72: Important helminth infections in Southeast Asia: diversity and potential for control and elimination. Part A (CA: Academic. San Diego, London, 2010$) 118$ - 120.

[9] A. Gunn, and S. Jane, Parasitology an integrated Approach, (Hoboken: John Wiley and Sons, 2012$) 91$.

[10] B. Gasser, Molecular tools-advances, opportunities and prospects, Vet Parasitol, 136, 2005, $69-89$.

[11] Q. Zhu, M. Podolska, J. S. Liu, H. Q. Yu, H. H. Chen, Z. X. Lin, C. B. Luo, H. Q. Song, and R. Q. Lin, Identification of Anisakid nematodes with zoonotic potential from Europe and China by single-strand conformation polymorphism analysis of nuclear ribosomal DNA. Parasitol Res, 101, 2007, 703-1707.

[12] F. Krammer, and T. Schnieder, Sequence heterogeneity in a repetitive DNA element of Fasciola, Int J Parasitol, 28, 1998, 1923 1929.

[13] S. Aldemir, Differentiation of cattle and sheep originated Fasciola hepatica by RAPD-PCR, Rev Med Vet, $157,2006,65-67$.

[14] K. Semenova, E. A. Romanova, I. I. Benediktov, and A. P. Ryskov, Analysis of genetic variability of Fasciola hepatica using the polymerase chain reaction with random primers. Genetika, 31, 1995, 273-275. 
[15] A. Romanova, S. K. Semenova, I. I. Benediktov, and A. P. Ryskov, Use of polymerase chain reaction for identifying the DNA of helminths from the genera Trichinella, Fasciola, Echinococcus, Nematodirus and Taenia, Parazitologiya, 31,1997, 53 - 65.

[16] R. Gunasekar, A. K. Tewari, C. Sreekumar, S. C. Gupta, and J. R. Rao, Elucidation of genetic variability among different isolates of Fasciola gigantica (giant liver fluke) using random-amplified polymorphic DNA polymerase chain reaction, Parasitol Res, 103, $2008,1075-108$

[17] B. Dawes, Advances in parasitology volume 3 AP (Burlington Elsevier, New York, 1965.) 61-62

[18] V. Periago, M. A. Valero, M. El Sayed, K. Ashrafi, A. El Wakeel, M. Y. Mohamed, M. Desquesnes, F. Curtale, and S. Mas-Coma, First phenotypic description of Fasciola hepatica/Fasciola gigantica intermediate from human endemic area of Nile Delta, Egypt. Inf. Gen, 8, 2008, $51-58$

[19] A. Valero, N. A. Darce, M. Panova, and S. Mas-Coma, Relationships between host species and morphometric patterns in Fasciola hepatica adults and eggs from the Northern Bolivian Altiplano hyper endemic region. Vet.Parasitol, 102, 2001, 85 - 100.

[20] M. Lofty, H. N. EL-Morshedy, M. A. EL-Hoda, M. M. EL-Tawila, , E. A. Omar, and H. F. Farag, Identification of the Egyptian species of Fasciola, Vet. Parasitol, 103, 2002, 323 - 332.

[21] K. Ashrafi, M. Valero, M. Panova, M. Periago, J. Massoud, and S. Mas-Coma, Phenotypic analysis of adults of Fasciola hepatica, Fasciola gigantic and intermediate forms from the endemic region of Gilan, Iran. Parasitol Int, 55, 2006, $249-60$.

[22] H. Sahba, F. Arfaa, I. Farahmandian, and H. Jalalit, Animal Fasciolasis in Khuzestan, Southwestern Iran, Parasitol Int, 58, 1972, 712 - 716 .

[23] A. Meshgi, Karimi and P. Shayan, Genetic Variation of Fasciola hepatica from Sheep, Cattle and Buffalo, 3(2), 2008, 71-78

[24] Y. Garedaghi, and M. Khakpour, Molecular differentiation of sheep and cattle isolates of Fasciola hepatica using RAPD-PCR, Razi Vac, 67, 2012,109- 115

[25] K. Semenova, E. V. Morozova, G. G. Chrisanfova, A. A. Asatrian, S. O. Movsessian, and A. P. Ryskov, RAPD variability and genetic diversity in two populations of liver fluke, Fasciola hepatica, Acta Parasitologica, 48, 2003, 125 - 130.

[26] J. McGarry and P. Ortiz, PCR-based differentiation of Fasciola species (Trematoda: Fasciolidae), using primers based on RAPDderived sequences, Annals of TropMed and Parasitol, 101, 2007, 415 - 421.

[27] S. Vazquez-Prieto, R. Vilas, M. Mezo, M. Gonzảlez-Warleta, F. M. Ubeira, and E. Paniagua, Allozyme markers suitable for population genetic analysis of Fasciola hepatica, Vet Parasitol, 176, 2011, $84-8$.

[28] R. Hudson, D. D. Boos, and N. L. Kaplan, A statistical test for detecting geographic subdivision, Mol Biol Evol, 9, 1992, 138 151 .

[29] T. Blair, T. Agatsuma, T. Watanobe, M. Okamoto, and A. Ito, Geographical genetic structure within the human lung fluke, Paragonimus westermani, detected from DNA sequences, Parasitol, 115, 1997, 411 - 417. 